\title{
STUDY OF ELECTROCHEMICAL BEHAVIOR OF TWO CHEMICALLY SIMILAR ACRIDINES: TACRINE AND 9-AMINOACRIDINE ON HANGING MERCURY DROP ELECTRODE
}

\author{
Wafa F. S. Badulla ${ }^{1,2 *}$, Weiam A. A. Hussein ${ }^{1,3,4}$ and Goksal Arli $^{2}$ \\ ${ }^{1}$ Department of Pharmaceutical Chemistry, Faculty of Pharmacy, Aden University, 6075, Aden, \\ Yemen \\ ${ }^{2}$ Department of Analytical Chemistry, Faculty of Pharmacy, Anadolu University, 26470, \\ Eskisehir, Turkey \\ ${ }^{3}$ Department of Pharmaceutical Chemistry, Faculty of Pharmacy, Anadolu University, 26470, \\ Eskisehir, Turkey \\ ${ }^{4}$ Department of pharmaceutical chemistry, Faculty of Pharmacy, Hail University, Hail, 2240 \\ Saudi Arabia
}

(Received April 21, 2021; Revised December 9, 2021; Accepted December 16, 2021)

\begin{abstract}
The electrochemical behavior of two chemically related acridine compounds: tacrine (TAC) and 9aminoacridine (9-AA) was investigated on a hanging mercury drop electrode (HDME). The electrochemical study was carried out by using Osteryoung square wave voltammetry (OSWV) and cyclic voltammetry (CV) techniques in the Britton-Robinson (B-R) buffer solution at $\mathrm{pH}=2.0-12.0, \mathrm{KCl}(0.1 / 0.2 / 0.3 \mathrm{M})$ and methanol $(0.0-50 \%)$ mixture as supporting electrolyte. TAC showed maximum current at $\mathrm{pH} 7.5$ while $9-\mathrm{AA}$ at $\mathrm{pH} 10, \mathrm{KCl}(0.3 \mathrm{M})$, and $10 \%$ methanol. The study of electrochemical reduction of 9-AA and TAC on the HDME by using CV resulted in a quasi-reversibility, mainly diffusion-controlled reaction. The reaction involved $1 \mathrm{e}^{-} / 1 \mathrm{H}^{+}$reduction at nitrogen atom in the case of the 9 -AA while the second process involved the $2 \mathrm{e}^{-} / 2 \mathrm{H}^{+}$reduction of the intra-cyclic azomethine group. The reduction peak potential of structurally related acridine compounds is influenced by the $\mathrm{pH}$ values and percentage of the organic solvent of the supporting electrolytes. Also, the study may provide insight into the electron transfer pathways of biological reactions of the acridines and their electrochemical behavior on the electrode.
\end{abstract}

KEY WORDS: Tacrine, 9-Aminoacridine, Cyclic voltammetry, Osteryoung square wave voltammetry, Hanging mercury dropping electrode

\section{INTRODUCTION}

Acridine is a heterocyclic alkaloid nucleus of anthracene. It has several chemical names such as; dibenzopyridine, 2,3,5,6-dibenzopyridine, and 10-azaanthracene (Figure 1a). It represents a medically active part of several pharmaceutical effective drugs for example; tacrine (TAC), aminoacridine (9-AA). These derivatives attracted much consideration because of their medicinal, physicochemical properties, and applications in many important chemical processes [1]. TAC (1,2,3,4-tetrahydro-9-aminoacridine) (Figure 1b) was the first centrally active, cholinesterase inhibitor (AchEI) approved by the US Food and Drug Administration for the treatment of patients with Alzheimer's disease in 1993. However, due to its hepatotoxicity, it was withdrawn from the market of many countries in 2013 [2]. Several newly synthesized hybrids were designed to combine its potent AChE inhibition with a low hepatotoxic effect [3-10]. Many pharmaceutical chemical laboratories have still used it as a reference drug to compare the AchEI potency of newly synthesized hybrids. The 9-AA (Figure 1c) displays a mild antiseptic and antimalarial activity [11]. It is considered the most effective base than other amino acridines. Many derivatives of 9AA have anti-Alzheimer's [12], antimalarial [13], anticancer [14] and others.

*Corresponding author. E-mail: aden.wf.77@gmail.com

This work is licensed under the Creative Commons Attribution 4.0 International License 


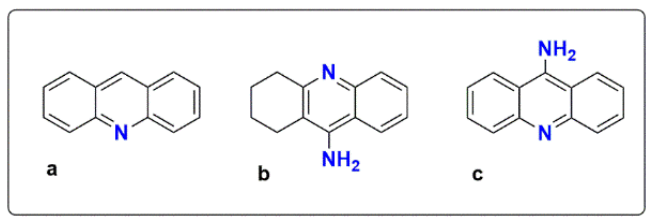

Figure 1. The chemical structure of (a) acridine, (b) TAC and (c) 9-AA.

The literature survey represented that, the electrochemical behavior of the TAC was investigated and it showed redox properties in an aqueous media, the determination of TAC on the dropping mercury electrode (DME), produced a complex signal that is $\mathrm{pH}$-dependent. The cyclic voltammetry at $\mathrm{pH} 7.5$ showed irreversible behavior with one cathodic peak. The adsorptive property of TAC was concentration-related. That means it was diffusion controlled at low concentration and adsorption at high concentration. The mechanism of electro-reduction is depend on the $\mathrm{pH}$ of the supporting electrolyte. The analysis of TAC by using differential pulse voltammetry (DPV) on the carbon electrode showed a poorly resolved anodic signal [15]. Another study revealed the possibility of oxidation of TAC and its metabolites on the carbon electrode by using DPV and CV technique in phosphate buffer at $\mathrm{pH} 2.8$. The CV showed only one anodic peak with a diffusion-controlled mechanism [16]. However, there were several analytical methods for the detection of TAC such as; HPLC, spectroscopic, and others, there is no space to mention them all herein.

On the other hand, there was no electrochemical study for the 9-AA and a limited number of studies that reported other analytical methods. Though, several studies reported using an electrode that was modified with 9-AA. The applications of 9-AA help to improve the electron transfer, to get better signal and separation of several biological constituents and pharmaceutical drugs [17$19]$.

Both selected compounds still have pharmaceutical and laboratory applications in several types of medical research. The current study aims to exhibit the power of electrochemistry to differentiate between the electrochemical behavior of these two closely related acridine compounds on HMDE. Furthermore, the inclusive study of the electrochemical behavior will be suitable in the explanation of the electron transfer pathways of biological reactions of the acridines which possess some pharmaceutical activities. Studying the electrochemical behavior of these compounds can be used in the future for electrochemical synthesis of TAC or 9-AA hybrids since there is a trend toward the synthesis of new hybrids to reduce the toxic effect of TAC or to improve their therapeutic effect by using electrochemical synthesis. Electrochemical synthesis has the advantage that there is no need for the addition of oxidizing or reducing agents which is considered the chief advantage of electrochemical synthesis [20-22].

\section{EXPERIMENTAL}

\section{Chemicals and reagents}

TAC and 9-AA (reagent grade 99\%) were obtained from Sigma-Aldrich. Chemicals and solutions (Analytical reagent grade) were used in this study. The supporting electrolyte is composed of BR, $\mathrm{KCl}$, and methanol. The BR buffers were made from boric acid, acetic acid, and phosphoric acid, all $0.04 \mathrm{M}$, and titrated to the anticipated value with $0.2 \mathrm{M} \mathrm{NaOH}$. The $\mathrm{KCl}$ solution (1.0-3.0 M) was prepared in water (Milli-Q), used as a supporting electrolyte. All solutions were reserved in a refrigerator $\left(\right.$ at $\left.4.0^{\circ} \mathrm{C}\right)$. 
Instruments

The study was accomplished by using a fully automated BAS-100B, a three-electrode voltammetric analyzer (Controlled growth mercury electrode (CGME) was used as the indicator electrode, while a platinum wire as the counter electrode, and an $\mathrm{Ag} / \mathrm{AgCl}$ electrode as the reference electrode). The data were analyzed with BAS-100B version 2.3 software. All analyses were performed at room temperature $\left(25 \pm 2{ }^{\circ} \mathrm{C}\right)$ with a glass cell $(10 \mathrm{~mL})$ connected to ultra-pure nitrogen gas $(99.999 \%)$ source for deoxygenation. A Mettler-Toledo $\mathrm{pH}$ meter was used to adjust the $\mathrm{pH}$ of the solutions. Ultrapure water was prepared by using a Milli-Q A10 Synthesis water purification system (Millipore, France).

Preparation of stock solution

The stock solution of TAC and 9-AA was prepared by dissolving in ultrapure water $(289.22 \mu \mathrm{g}$ $\mathrm{mL}^{-1}$ and $248.71 \mu \mathrm{g} \mathrm{mL}^{-1}$, respectively), and then sonicated for $10 \mathrm{~min}$ to increase dissolution. The solutions for further study were prepared from the stock solution by adequate dilution with supporting electrolytes.

Voltammetric procedures

In this study, to obtain information on the electrode reaction mechanism, the CV technique was used over the potential changes from $0.2 \mathrm{~V}$ to $-1.50 \mathrm{~V}$ at various scan rates $(\mathrm{v})$ from $10 \mathrm{mV} \mathrm{s}^{-1}$ to $1000 \mathrm{mV} \mathrm{s}^{-1}$. The application of the OSWV technique was also investigated, which was used for the determination of two compounds in the standards. The square-wave voltammograms were accomplished using the following experimental parameters: The scan rate $20 \mathrm{mVs}^{-1}$, pulse amplitude $50 \mathrm{mV}$, sample width $17 \mathrm{~ms}$, pulse width $50 \mathrm{~ms}$, pulse period $200 \mathrm{~ms}$, and purge time of 5 min. A known volume of standard solutions for each compound was added to the electrochemical cell with supporting electrolyte and was used for the examination after purging with purified nitrogen for $30 \mathrm{~s}$. Each measurement was performed on a fresh mercury drop at room temperature. The same steps were applied to the blank solution.

\section{RESULTS AND DISCUSSION}

\section{Optimization of the OSWV technique}

Throughout the development of the OSWV to investigate the electrochemical behavior of TAC and 9-AA, the content of the supporting electrode was examined because it influences the medium and boundaries of the electrode surface and might modify the type and kinetics of the electrode reaction [23].

Influence of supporting electrolyte and its $\mathrm{pH}$

The $\mathrm{pH}$ of the electrolyte solution influences the electrode reaction so the reduction behavior was studied for both compounds over the $\mathrm{pH}$ range $(2.0,4.0,6.0,8.0,10,12)$ in the BR buffer by the OSWV technique. Both compounds showed one well-defined reduction peak in the potential range of -0.2 to $-1.50 \mathrm{~V}$ vs. $\mathrm{Ag}|\mathrm{AgCl}| \mathrm{KCl}$ sat. The maximum peak current was attained at $\mathrm{pH} 7.5$ for TAC and $\mathrm{pH} 10$ for 9-AA. According to these results, it can assume two different electroreduction processes for $\mathrm{TAC}$ and $9-\mathrm{AA}$; that involved $1 \mathrm{e}^{-} / 1 \mathrm{H}^{+}$reduction at nitrogen atom at $\mathrm{pH} 10$ in the case of the 9-AA while the second process involved the $2 \mathrm{e}^{-} / 2 \mathrm{H}^{+}$reduction of the intracyclic azomethine group at investigated $\mathrm{pH} 7.5$ for TAC. Generally, it has been reported that the 
reduction of the acridines is always carried out with the presence of a base, i.e. $\mathrm{pH}>7$ and 1,4,5,8-

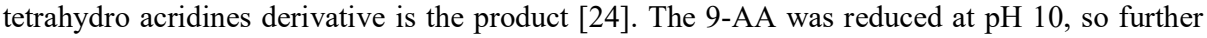
energy was required for reduction more than TAC due to low hydrogen ion concentration at $\mathrm{pH}$ 10. Therefore, the cathodic reduction peak potential shifted to a more negative potential. Several concentrations of $\mathrm{KCl}(0.1 / 0.2 / 0.3 \mathrm{M})$ were investigated for both standards. There were no distinct differences in the current value by changing the molarity of the $\mathrm{KCl}$ so, the $0.3 \mathrm{M} \mathrm{KCl}$ was selected because the current was stable. The influence of the organic solvent on the electrochemical behavior was studied by using methanol. Several methanol percentages $(50,40$, $30,20,10$, and $0 \%$ ) were examined. The well-defined peak shape and the high peak current were obtained by using $10 \%$. The final supporting electrolyte for determination of TAC and 9-AA compounds concerning the peak current, low non-faradaic current, and the best repeatability was attained by using $\mathrm{BR}$ buffer at $\mathrm{pH}=7.5$, and 10 , respectively containing $0.3 \mathrm{M} \mathrm{KCl}$ and $10 \%$ methanol.

\section{Redox behavior of TAC and 9-AA}

The electrochemical behavior of both compounds was investigated by examining the standard solutions using the $\mathrm{CV}$ technique. One discrete cathodic peak was detected in the case of 9-AA at about $-1.3 \mathrm{~V}$ and one anodic peak. In the case of TAC one broad peak was observed at about 0.95-1.00 $\mathrm{V}$ and one at the anodic potential. The reduction of 9-AA can occur via proton reduction but in the case of TAC intra-cyclic azomethine group of TAC merged with the proton reduction for this reason the reduction peak was broad.

By calculating the Ipa/Ipc the value is close to 1 for TAC (1.07) and 9-AA (1.14). This indicates that the electrode reaction is quasi-reversible also the minor negative shift with increasing the scan rates confirms the quasi-reversibility [25], as well as the reversibility of electrode reaction [26]. The anticipated mechanism for electrochemical reduction of both compounds (are given in Scheme 1 and 2).

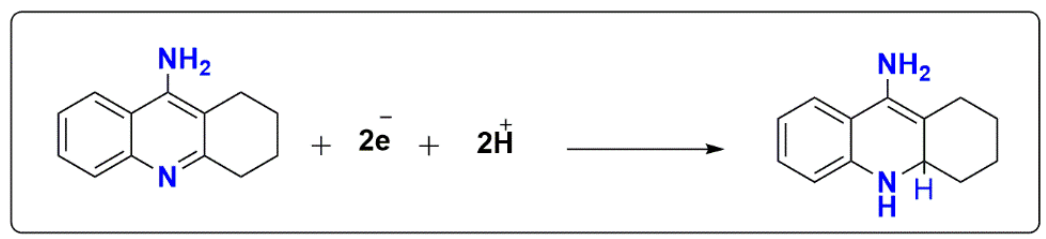

Scheme 1. Proposed reduction mechanism of TAC.

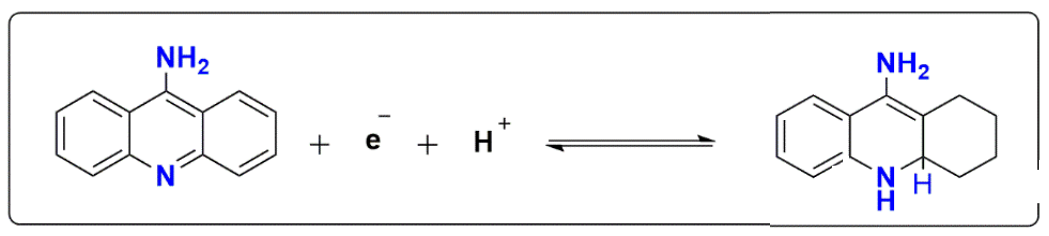

Scheme 2. Proposed reduction mechanism of 9-AA.

There was no redox peak for the blank solution at the whole working potential range. The type of the electrochemical mechanism (diffusion or adsorption-controlled) was determined by applying different scan rates $(v)$ from $25 \mathrm{mV} \mathrm{s}^{-1}$ to $1000 \mathrm{mV} \mathrm{s}^{-1}$ and the performance of TAC and 9-AA was examined in BR buffer $\mathrm{pH} 7.5$ and 10 respectively in the potential range from $\quad-0.8$ 
to $-1.6 \mathrm{~V}$. There was one broad-defined cathodic peak at the potential of - 0.95 for TAC and one well defined-peak $-1.35 \mathrm{~V}$ for 9-AA with a negative shift by increasing scan rate. The anodic peak was clear in the case of TAC while 9-AA had a less well-defined-peak. (Figure 2a, b).

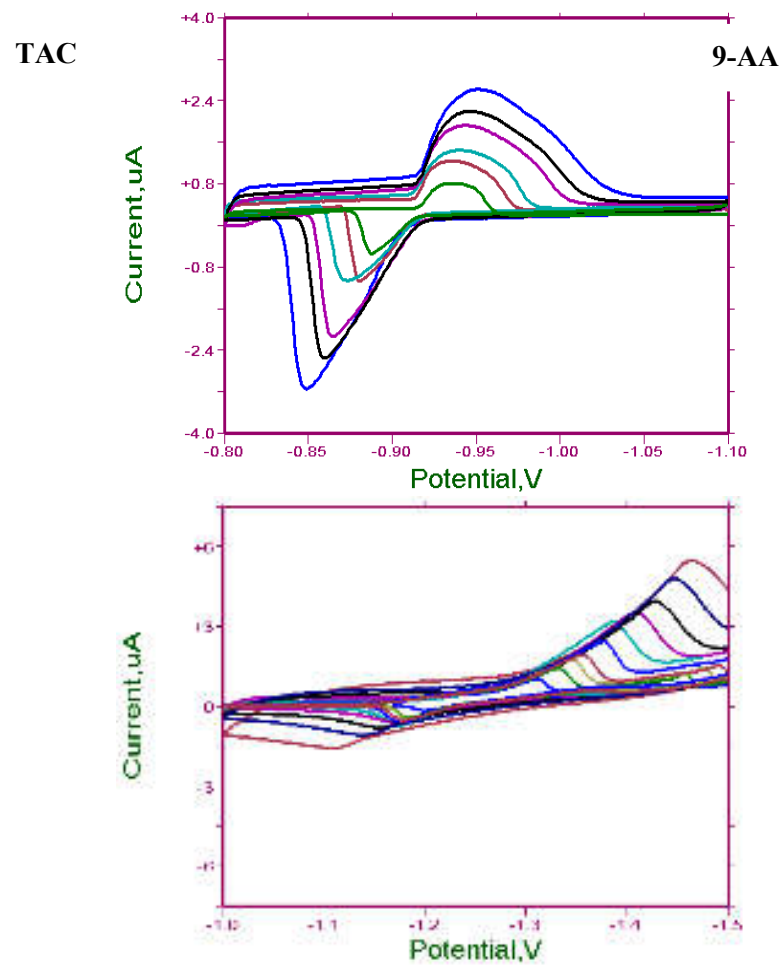

Figure 2. Cyclic voltammograms of (a) TAC were recorded in the $\mathrm{BR}$ buffer of $\mathrm{pH}=7.5$ and (b) 9-AA in the BR buffer of $\mathrm{pH}=10$ on HMED at various scan rates.

The relationship between the peak intensity (Ipc) of both compounds and the square root of the scan rate $\left(v^{1 / 2}\right)$ was linear. This suggests that the electrochemical process is mainly diffusion controlled. The correlation can be represented by the following equation:

For TAC: $\operatorname{Ipc}(\mathrm{A})=1.614 \times 10^{-7} \mathrm{~V}^{1 / 2}\left(\mathrm{mV} \mathrm{s}^{-1}\right)^{1 / 2}-3.07 \times 10^{-7} \quad\left(\mathrm{r}^{2}=0.9984\right)$

For 9-AA: $I \mathrm{pc}(\mathrm{A})=1.687 \times 10^{-7} \mathrm{~V}^{1 / 2}\left(\mathrm{mV} \mathrm{s}^{-1}\right)^{1 / 2}-5.198 \times 10^{-7} \quad\left(\mathrm{r}^{2}=0.9955\right)$

The correlation between the logarithm of the peak current $(\log I \mathrm{pc})$ and the logarithm of the scan rate $(\log v)$ also agree with the obtained data. The equation of the relationship can be represented by the equation:

For TAC: $\log$ Ipc $(\mathrm{A})=0.579 \log v\left(\mathrm{mV} \mathrm{s}^{-1}\right)-7.049\left(\mathrm{r}^{2}=0.9992\right)$

For 9-AA: $\log I \mathrm{pc}(\mathrm{A})=0.509 \log v\left(\mathrm{mV} \mathrm{s}^{-1}\right)-6.650\left(\mathrm{r}^{2}=0.9950\right)$

The slope of both equations is close to 0.5 which means the electrode reaction is diffusion controlled. If the slope is close to 1 that means the reaction is chiefly adsorption controlled [ 27 , 28]. 
Furthermore, the number of electrons involved in the reduction of the TAC and 9-AA was calculated. For quasi-reversible and reversible electrode processes, Epc is dependent on $\log \mathrm{v}$ and expressed by Laviron equation [29].

$$
E \rho c=\mathrm{E}^{\circ}+\left(\frac{2.303 \mathrm{RT}}{\alpha \mathrm{nF}}\right) \log \left(\frac{R T K^{\circ}}{\alpha \mathrm{nF}}\right)+\left(\frac{2.303 \mathrm{RT}}{\alpha \mathrm{nF}}\right) \log v
$$

where $\alpha$ is the symbol of transfer coefficient, $\mathrm{k}^{\circ}$ the standard heterogeneous rate constant of the reaction, $\mathrm{n}$ is the number of electrons transferred, $v$ the scan rate, and $\mathrm{E}^{\circ}$ is the formal redox potential. Consequently, the value of $\alpha$ can be readily calculated from the slope of the Epc vs. logv. In this electrochemical reaction, the slope is -0.0487 for TAC and -0.918 for $9-\mathrm{AA}$, using T $=298 \mathrm{~K}, \mathrm{R}=8.314 \mathrm{~J} \mathrm{~mol} \mathrm{~K}^{-1}$, and $\mathrm{F}=96480 \mathrm{C} \mathrm{mol}^{-1}$, the $\alpha$ was calculated to be 2.936 . According to Bard and Faulkner [30], $\alpha$ can be found between 0.5 and 0.7 for quasi-reversible reactions. By taking 0.5 for $\alpha$ value, the number of electrons transferred in the TAC reduction was calculated as $\sim 2.4$ and 1.2 electrons for 9-AA. This value approves the theoretical statement of the number of electron transfers as revealed above.

\section{Validation of the developed method}

The linearity, LOD, LOQ, and developed method was evaluated according to International Conference on Harmonization ( $\mathrm{ICH}$ ) guidelines [31]. A linear relation was found between current and concentration. The LOD and LOQ were calculated as LOD $(k=3.3)$ and LOQ $(k=10)$, the precision is essential to obtain reliable results so measurements of intra-day and inter-day precision were carried. The related data is represented in Table 1.

Table 1. Validation parameters for the developed method.

\begin{tabular}{|l|l|l|}
\hline & TAC & 9 A-A \\
\hline Linear dynamic range $\left(\mu \mathrm{g} \mathrm{mL}^{-1}\right)$ & $26-91$ & $13-26$ \\
\hline Slope $(\mathrm{b})$ & 33.42 & 14.77 \\
\hline Intercept $(\mathrm{a})$ & 259.4 & 13.80 \\
\hline Regression coefficient $\left(\mathrm{R}^{2}\right)$ & 0.9992 & 0.9996 \\
\hline Limit of detection LOD $\left(\mu \mathrm{g} \mathrm{mL}^{-1}\right)$ & 2.85 & 0.75 \\
\hline Limit of quantification LOQ $\left(\mu \mathrm{g} \mathrm{mL}^{-1}\right)$ & 9.5 & 2.5 \\
\hline Precision for 3 concentrations & $1.2-0.83$ & $2.5-1.16$ \\
\hline
\end{tabular}

\section{CONCLUSION}

To sum up, a comprehensive electrochemical study of TAC and 9-AA at HMDE was carried out over a large $\mathrm{pH}$ range, $\mathrm{KCl}$ molarity, and methanol percentage. From the aforementioned study results, below conclusions can be outlined: (1) The reduction process of TAC and 9-AA is a quasireversible reaction. (2) The maximum current was at $\mathrm{pH} 7.5 \mathrm{BR}$ buffer, $10 \%$ methanol, and 0.3 $\mathrm{M} \mathrm{KCl}$. supporting electrolyte in the case of TAC and at $\mathrm{pH} 10$ for 9-AA. (3) The peak currents are diffusion-controlled. (4) The electrode reaction for TAC in the $\mathrm{pH} 7.5$ involved $2 \mathrm{e}^{-} / 2 \mathrm{H}^{+}$while, the electrode reaction for 9-AA in $\mathrm{pH} 10$ involved $1 \mathrm{e}^{-/} / 1 \mathrm{H}^{+}$. (5) Both compounds can be determined by using OSWV.

The reduction peak potential of structurally related acridine compounds is influenced by the $\mathrm{pH}$ values and percentage of the organic solvent of the supporting electrolytes. Also, the study may reveal insight into the electron transfer pathways of biological reactions of the acridines and their electrochemical behavior on the electrode.

The current study has advantages over the previously developed method for TAC [15] because it used an OSWV which is more sensitive than the DPP, uses a low amount of mercury in contrast 
to the polarographic method so it can be considered safer, needs less time per sweep. The previous study did not use methanol as a supporting electrolyte which may be an advantage but the current was more stable and the regression of the calibration curve also improved. Another previously mentioned study use carbon electrodes [16], but the present study used mercury. The advantages of mercury exceed its disadvantages, as it is known that a new surface is produced for each analysis so no contamination occurs from the previous analysis, has a wide potential range (from +0.4 to $-2.5 \mathrm{~V}$ corresponding to supporting electrolyte), does not require polishing, has high hydrogen over potential which makes it the best electrode for the cathodic reaction. The disadvantage of its toxicity can be reduced by taking special care during use and discarding.

\section{REFERENCES}

1. Kumar, R.; Kaur, M.; Kumari, M. Acridine: A versatile heterocyclic nucleus. Acta Pol. Pharm. 2012, 69, 3-9.

2. Watkins, P.B.; Hyman, J.Z.; Margaret, J.K.; Stephen, I.G.; Karen. W.L. Hepatotoxic effects of tacrine administration in patients with Alzheimer's disease. JAMA 1994, 271, 992-998.

3. Khoury, R.; Patel, K.; Gold, J.; Hinds, S.; Grossberg, G.T. Recent progress in the pharmacotherapy of Alzheimer's disease. Drugs Aging. 2017, 34, 811-820.

4. Korabecny, J.; Musilek, K.; Holas, O.; Nepovimova, E.; Jun, D.; Zemek, F.; Opletalova, V.; Patocka, J.; Dohnal, V.; Nachon, F.; Hroudova, J.; Fisar, Z.; Kuca K. N-(bromobut-3-en-2yl)-7-methoxy-1,2,3,4-tetrahydroacridin-9-amine as a cholinesterase inhibitor with regard to Alzheimer's disease treatment. Molecules 2010, 15, 8804-8812.

5. Korabecny, J.; Andrs, M.; Nepovimova, E.; Dolezal, R.; Babkova, K.; Horova, A.; Malinak, D.; Mezeiova, E.; Gorecki. L.; Sepsova, V.; Hrabinova, M.; Soukup, O.; Jun, D.; Kuca, K. 7Methoxytacrine- $p$-anisidine hybrids as novel dual binding site acetylcholinesterase inhibitors for Alzheimer's disease treatment. Molecules 2015, 20, 22084-22101.

6. Košak, U.; Brus, B.; Knez, D.; Šink, R.; Žakelj, S.; Trontelj, J.; Pišlar, A.; Šlenc, J.; Gobec, M.; Živin, M. Tratnjek, L.; Perše, M.; Sałat, K.; Podkowa, A.; Filipek, B.; Nachon, F.; Brazzolotto, X.; Więckowska, A.; Malawska, B.; Stojan, J.; Raščan, I.M.; Kos, J.; Coquelle, N.; Colletier, J.-P.; Gobec, S. Development of an in vivo active reversible butyrylcholinesterase inhibitor. Sci. Rep. 2016, 6, 39495.

7. Panek, D.; Wieckowska, A.; Wichur, T.; Bajda, M.; Godyn, J.; Jonczyk, J.; Mika, K.; Janockova, J.; Soukup, O.; Knez, D. Korabecny, J.; Gobec, S.; Malawska, B. Design, synthesis and biological evaluation of new phthalimide and saccharin derivatives with alicyclic amines targeting cholinesterases, beta-secretase and amyloid-beta aggregation. Eur. J. Med. Chem. 2017, 125, 676-695.

8. Wu, W.Y.; Dai, Y.C.; Li, N.G.; Dong, Z.X.; Gu,T.; Shi, Z.H.; Xue, X.; Tang, Y.P.; Duan, J.A. Novel multitarget-directed tacrine derivatives as potential candidates for the treatment of Alzheimer's disease. J. Enzyme Inhib. Med. Chem. 2017, 32, 572-587.

9. Sawatzky, E.; Wehle, S.; Kling, B.; Wendrich, J.; Bringmann, G.; Sotriffer, C.A.; Heilmann, J.; Decker, M. Discovery of highly selective and nanomolar carbamate-based butyrylcholinesterase inhibitors by rational investigation into their inhibition mode. J. Med. Chem. 2016, 59, 2067-2082.

10. Spilovska, K.; Korabecny, J.; Sepsova, V.; Jun, D.;Hrabinova, M.; Jost, P.; Muckova, L.; Soukup, O.; Janockova, J.; Kucera, T. Dolezal, R.; Mezeiova, E.; Kaping, D.; Kuca, K. Novel tacrine-scutellarin hybrids as multipotent anti-Alzheimer's agents: Design, synthesis, and biological evaluation. Molecules 2017, 22, 1006.

11. Wainright, M. Acridine - a neglected antibacterial chromophore. J. Antimicrob. Chemother. 2001, 47, 1-13.

12. Hussein, W.; Sağlı, B.N.; Levent, S.; Korkut, B.; Ilgın, S.; Özkay. Y.; Kaplancıklı, Z.A. Synthesis and biological evaluation of new cholinesterase inhibitors for Alzheimer's disease. Molecules 2018, 23, 2033. 
13. Fernández-Calienes Valdés, A. Acridine and acridinones: Old and new structures with antimalarial activity. Open J. Med. Chem. 2011, 5, 11-20.

14. El-Sheshtawy, H.S.; Assran, A.S.; Abou Baker, M.A. Synthesis, structural characterization, spectroscopic properties, and theoreticalinvestigations of aminoacridine derivatives. Polycycl. Aromat. Comp. 2019, 39, 1-13.

15. Bollo, S.; Munoz, L.; NuÂnÄez-Vergara, L.J.; Squella, J.A. Electrochemical characterization of tacrine, an antialzheimer's disease drug, and its determination in pharmaceuticals. Electroanalysis 2000, 12, 376-382.

16. Aparicio, I.; Callejón, M.; Jiménez, J.C.; Bello, M.A.; Guiraúm, A. Electrochemical oxidation at carbon paste electrode of tacrine and 1-hydroxytacrine and differential pulse voltammetric determination of tacrine in pharmaceuticals and human urine. Analyst 2000, 125, 2016-2019.

17. Fang, B.; Liu, H.; Wang, G.; Zhou, Y.; Jiao, S.; Gao, X. Preparation of poly(9-aminoacridine)modified electrode and its application in the determination of dopamine and ascorbic acid simultaneously. J. Appl. Polym. Sci. 2007, 104, 3864-3870.

18. Fang, B.; Liu, H.; Wang, G.; Zhou, Y.; Li, M.; Yua, Y.; Zhang, W. The electrochemical behavior and direct determination of tyrosine at a glassy carbon electrode modified with poly (9-aminoacridine). Ann. Chim. 2007, 97, 3864-3870.

19. Güney, S.; Yıldız, G. Determination of tryptophan using electrode modified with poly(9aminoacridine) functionalized multi-walled carbon nanotubes. Electrochim. Acta 2011, 57, 290-296.

20. Matthews, M.A. Green electrochemistry. Examples and challenges. Pure and Appl. Chem. 2001, 73, 1305-1308.

21. Sotgiu, G. Easy electrochemical synthesis of 2-amino-4-aryl-3-cyano-5-ethoxycar-bonyl-6methyl-4H-pyrans in the absence of supporting electrolyte. Lett. Org. Chem. 2008, 5, 555558.

22. Yoshida, J.I.; Kataoka, K.; Horcajada, R.; Nagaki, A. Modern strategies in electroorganic synthesis. Chem. Rev. 2008, 108, 2265-2299.

23. Wang, J. Analytical Electrochemistry, 3rd ed., John Wiley and Sons, Inc: Canada; 2000.

24. Ram, V.J.; Sethi, A.; Nath, M.; Pratap, R. The Chemistry of Heterocycles, Chemistry of Six to Eight Membered N,O, S, P, and Se Heterocycles. 1st ed., Elsevier: Amsterdam; 2019.

25. Diculescu, V.C.; Militaru, A.; Shah, A.; Qureshi, R.; Laura, Tugulea, L.; Oliveira- Brett, A.M. Redox mechanism of lumazine at a glassy carbon electrode. J. Electroanal. Chem. 2010, 64, $1-7$.

26. Marken, F.; Neudeck, A.; Bond, A.M. In Electroanalytical Methods, 2nd ed., Springer: Heidelberg; 2010.

27. Timbola, A.K.; Souza, C.D.; Soldi, C.; Pizzolatti, M.G.; Spinelli, A. Electro-oxidation of rutin in the presence of $p$-toluenesulfinic acid. J. Appl. Electrochem. 2007, 37, 617-624.

28. Burcu, D.T.; Palabıyık, B.B.; Uslu, B.; Ozkan, S.A. Multi-walled carbon nanotube modified glassy carbon electrode as a voltammetric nanosensor for the sensitive determination of antiviral drug valganciclovir in pharmaceuticals. Sensor Actuat. B-Chem. 2013, 177, 841-847.

29. Laviron, E.; Roullier, L.; Degrand, C. A multilayer model for the study of space distributed redox modified electrodes: Part II. Theory and application of linear potential sweep voltammetry for a simple reaction. J. Electroanal.Chem. 1980, 112, 11-23.

30. Bard, A.J.; Faulkner, L.R. Electrochemical Methods: Fundamentals and Applications, 2nd ed., John Wiley and Sons: New York; 2001.

31. ICH-Topic Q2(R1), (2005). Validation of Analytical Procedures: Text and Methodology. Harmonized Tripartite Guideline, pp.1-13. Available at: http://www.ich.org/pdfIC H/Q2A. Assessed 04 March 2017. 